\title{
Molecular characterization, expression and localization of a peroxiredoxin from the sheep scab mite, Psoroptes ovis
}

\author{
C. M. McNAIR ${ }^{1}$, A. J. NISBET ${ }^{1}$, P. F. BILLINGSLEY ${ }^{2}$ and D. P. KNOX ${ }^{1 *}$ \\ ${ }^{1}$ Moredun Research Institute, Pentlands Science Park, Bush Loan, Penicuik EH26 0PZ, Scotland \\ ${ }^{2}$ Sanaria Inc., 12115 Parklawn Drive, Ste L, Rockville, MD 20852-1730, USA
}

(Received 29 October 2008; revised 10 December 2008; accepted 10 December 2008; first published online 6 February 2009)

\section{S U M MAR Y}

The sheep scab mite, Psoroptes ovis, induces an intensely pruritic exudative dermatitis which is responsible for restlessness, loss of appetite and weight loss. Within the first $24 \mathrm{~h}$ of infection, there is a rapid inflammatory influx of eosinophils and apoptosis of the keratinocytes at the site of infection. The former cell type is capable of a sustained respiratory burst, toxic products of which may directly damage the mite and also contribute to lesion formation. Analysis of a $P$. ovis expressed sequence tag (EST) database identified a number of antioxidant enzyme-encoding sequences, including peroxiredoxin (thioredoxin peroxidase EC 1.11.1.15), all of which may help the mite endure the potentially toxic skin environment. A full length sequence encoding $P_{0}$-TPx, a protein of 206 amino acids which showed high homology to a peroxiredoxin from the salivary gland of the tick Ixodes scapularis, was amplified from P. ovis cDNA. Recombinant Po-TPx was expressed in bacteria and antiserum to this protein was used to localize native Po-TPx in mite sections. Peroxiredoxin was localized, amongst other sites, to a subpharyngeal region in mite sections. The recombinant protein was recognized by sera from sheep infested with the mite suggesting that it may be secreted or excreted by the mite and interact with the host immune response.

Key words: Psoroptes ovis, antioxidant, immunity, reactive oxygen species.

\section{INTRODUCTION}

Sheep scab is a major welfare problem for the UK farming industry, resulting in losses of around $£ 8$ million per year (Nieuwhof and Bishop, 2005). The lesion from infestation is an allergic inflammatory dermatitis associated with eosinophil infiltration of the infection site (van den Broek et al. 2000). In the majority of cases the lesion resolves after several (6-10) weeks, and a semi-protective immune response can be demonstrated after challenge infection (van den Broek et al. 2000). The disease is currently controlled using a range of acaricides, but resistance to these is emerging (Synge et al. 1995; Clark et al. 1996). To avoid this, new control options need to be explored with vaccination representing one of the more promising alternatives (Nisbet and Huntley, 2006). Sheep exposed to natural infection do acquire immunity as judged by reduced lesion size and intensity on secondary infestation, suggesting that vaccine-based control may be feasible. Indeed, Smith and Pettit (2004) immunized sheep with a watersoluble mite extract and, after challenge, reported slowed lesion development and a 13 -fold reduction in mite numbers compared to control sheep given

* Corresponding author: Moredun Research Institute, Pentlands Science Park, Bush Loan, Penicuik EH26 0PZ, Scotland. Tel: + $44(0) 131445$ 5111. Fax: + $44(0) 131$ 445 6235. E-mail: Dave.Knox@moredun.ac.uk adjuvant alone, demonstrating the potential impact of vaccination on infection. For the successful progress of vaccine development against sheep scab mite it is essential that we have a better understanding of the interactions between the ovine immune system and the parasite (Nisbet et al. 2008).

Eosinophils engaged in phagocytosis have the capacity for the prolonged release of the reactive oxygen species $\mathrm{O}_{2}{ }^{-}$(superoxide radical; Tauber et al. 1979) and this may contribute both to their unique microbicidal profile and to the capacity of eosinophils to injure host tissues in some eosinophilic syndromes. Antioxidant enzymes which may, in part, facilitate immune evasion, are commonly found in parasite secretions. For example, the deer tick, Ixodes scapularis, secretes superoxide dismutase and thioredoxin peroxidases (commonly termed peroxiredoxins), amongst other products, from its salivary glands (Ribeiro et al. 2006). The hard tick Haemaphysalis longicornis, which infests a variety of hosts including sheep and cattle, expresses a peroxiredoxin at high levels in its salivary glands and this protein is recognized by sera from rabbits repeatedly exposed to infestation ('Tsuji et al. 2001). A salivary glutathione peroxidase from $I$. scapularis is an immunodominant antigen (Das et al. 2001), suggesting it may be a target for host protective immune responses. A variety of other parasites release antioxidant enzymes which may protect them from oxidative killing by host products (e.g. LoVerde, 1998). In addition, 
vaccination with free-radical scavenging enzymes has been shown to stimulate host protective immunity against trematodes (Shalaby et al. 2003) and nematodes (Liddell and Knox, 1998).

Very little is known about the variety of antioxidant enzymes in $P$. ovis and their function. As noted above, the dermal lesion is heavily infiltrated by eosinophils which can generate a range of reactive oxidant species (Tauber et al. 1979) and it is possible that antioxidant enzymes play important roles in the early stages of mite establishment on the host. An expressed sequence tag (EST) survey of genes expressed in $P$. ovis identified several sequences with homology to antioxidant enzymes including superoxide dismutase, glutathione S-transferases and peroxiredoxins, the latter being represented more frequently in the dataset insinuating potential relative abundance (Kenyon et al. 2003). Secreted peroxiredoxin is linked to alternatively activated macrophage expression in hosts infected with the liver fluke, Fasciola hepatica (Donelly et al. 2005), leading to a Th2-type immune response in the host, which is possibly to the parasite's advantage. It has been suggested that the host immune response observed during the onset of sheep scab benefits the mite more than the sheep (Huntley et al. 2005), so it is possible that mite secretions interact with the host immune response and cause lesion proliferation, which may help the mite to feed and persist on the host for longer periods.

Here we sought to demonstrate peroxiredoxin activity in mite extracts, isolated a full-length cDNA encoding a full-length protein, expressed this as a recombinant protein $(\mathrm{r} P o-\mathrm{TPx})$ in bacteria and used $\mathrm{r} P o-\mathrm{TPx}$ to raise antiserum for application in immunolocalization studies and to seek evidence for immunogenicity during mite infestation in sheep.

\section{MATERIALS AND METHODS}

\section{Parasite material}

Mites $(16.9 \mathrm{~g})$ were collected from donor sheep (Dorset breed aged 1 year) and water-soluble (S1) and membrane-associated (S2) mite extracts were prepared as described by Smith and Pettit (2004). The extracts were pooled, filtered and the mixture was dialysed overnight at $4{ }^{\circ} \mathrm{C}$ against $10 \mathrm{~mm}$ Tris, $0 \cdot 1 \%$ Tween $20,0 \cdot 02 \% \mathrm{NaN}_{3}(\mathrm{pH} 7 \cdot 4)$, centrifuged at $100000 \boldsymbol{g}$ for $1 \mathrm{~h}$, and the supernatant was then filtered (pore size: $0 \cdot 45 \mu \mathrm{m}$ ). The protein concentration of the resulting soluble extract was estimated using a Cecil CE2041 spectrophotometer.

\section{Peroxiredoxin (thioredoxin peroxidase) activity}

Mite extract $(25 \mu \mathrm{l})$ was mixed with $0.7 \mathrm{ml}$ of mixed substrate solution $(0 \cdot 1 \mathrm{~m}$ buffer, $8 \mathrm{~mm}$ EDTA, $8 \mathrm{~mm}$ sodium azide, $120 \mu \mathrm{M}$ NADPH, $40 \mu \mathrm{M}$ reduced thioredoxin, $30 \mu \mathrm{M}$ potassium cyanide, and $0.025 \mathrm{U}$ thioredoxin reductase) and $0.7 \mathrm{ml}$ of a $0.003 \%$ solution of $\mathrm{H}_{2} \mathrm{O}_{2}$. The absorbance of the solution at $340 \mathrm{~nm}$ was monitored for $10 \mathrm{~min}$, with readings being taken every min. The optimum $\mathrm{pH}$ was established by performing the assay over the $\mathrm{pH}$ range 3 to 10 (buffers used: $\mathrm{pH} 3-6,0 \cdot 1$ M sodium acetate; $\mathrm{pH} 7-8,0 \cdot 1 \mathrm{~m}$ phosphate; $\mathrm{pH} 9-10,0 \cdot 1 \mathrm{M}$ glycine). Triplicate assays were performed at each $\mathrm{pH}$. Triplicate control assays containing no mite extract were also performed at each $\mathrm{pH}$ point.

\section{Amplification of peroxiredoxin-encoding $c D N A$ and sequence analysis}

An expressed sequence tag (EST, Accession number BQ834914) was identified in the $P$. ovis EST collection (http://www.nematodes.org/Neglected Genomes/ARTHROPODA/Chelicerata.html) which showed high homology to a peroxiredoxin from the salivary glands of the deer tick, I. scapularis (Ribeiro et al. 2006), contained a putative initiation codon but did not encode the entire predicted enzyme peptide backbone. The entire open reading frame was amplified directly from a cDNA library constructed using RNA extracted from mixed stage and gender $P$. ovis (Nisbet et al. 2008) using a forward primer (5'-ATGGCAGTGAAGAATCCGCTAT-3') incorporating the predicted initiation codon and a reverse primer (5'-TGCGGCCGCATGCATAAGCTT-3') to the cloning vector used to produce the library (TriplEx2, Clontech). Reaction mixtures comprised (final concentrations in $30 \mu \mathrm{l}$ reactions): $1 \times \mathrm{NH}_{4}$ buffer, $2 \mathrm{~mm} \mathrm{MgCl}_{2}, 0 \cdot 1 \mathrm{~mm} \mathrm{dNTPs}, 0 \cdot 3 \mu \mathrm{M}$ forward primer, $0 \cdot 3 \mu \mathrm{M}$ reverse primer, 3 units Taq polymerase (Bioline) and $5 \mu \mathrm{l}$ of DNA template. PCR conditions were $94{ }^{\circ} \mathrm{C}$ for $5 \mathrm{~min}$; followed by 30 cycles of $94{ }^{\circ} \mathrm{C}$ for $15 \mathrm{sec}, 58{ }^{\circ} \mathrm{C}$ for $30 \mathrm{sec}$ and $72{ }^{\circ} \mathrm{C}$ for $90 \mathrm{sec}$; an extension period at $72{ }^{\circ} \mathrm{C}$ for $10 \mathrm{~min}$, then held at $4{ }^{\circ} \mathrm{C}$. The resulting amplicon was ligated into pGEM ${ }^{\circledR}$-T cloning vector (Promega), and used to transform Escherichia coli-competent cells (strain JM109). Plasmid DNA was isolated from the cells and sequenced on a MegaBACE 500 capillary sequencer using 'DYEnamic' ET terminator chemistry (GE Healthcare).

Further analyses of the sequence and the deduced amino acid sequence were performed using the DNAstar software (DNAstar Inc.). Database searches were performed on the NCBI server (www. ncbi.nlm.nih.gov/blast). The predicted protein, Po-TPx, was analysed for the presence of a signal peptide using the SignalP server (Dyrløv Bendtsen et al. 2004, www.cbs.dtu.dk/services/SignalP). A phylogenetic tree was constructed using Neighbourjoining analysis with representative TPx sequences from a variety of eukaryotes. The neighbour-joining tree was bootstrapped 1000 times using Clustal X 
(Jeanmougin et al. 1998) and the resulting tree viewed with TREEVIEW.

\section{Expression of peroxiredoxin}

The full-length coding sequence was amplified from plasmid cDNA using gene specific primers (Forward 5'-AATTCGGATCCGAAGAATCCGCTATGGATGCCC-3'; Reverse 5'-CCGCAAGCTTAACTGATCGGCCGACTGGTA-3') which incorporated recognition sites for the restriction enzymes BamHI and HindIII to facilitate subcloning into the pET22b (Novagen) vector. PCR conditions were essentially as described earlier except that the primer annealing temperature was $52{ }^{\circ} \mathrm{C}$. The resultant PCR product was ligated into the $\mathrm{pET} 22 \mathrm{~b}$ vector and used to transform BL21-CodonPlus ${ }^{\circledR}$ (DE3)-RIL E. coli (Stratagene) cells. Individual colonies were selected and grown overnight in LB medium at $37^{\circ} \mathrm{C}$, and protein expression induced by the addition of $1 \mathrm{~mm}$ isopropyl- $\beta$-D-thiogalacto-pyranoside (IPTG). Bacterial cells were pelleted by centrifugation at $2000 \boldsymbol{g}$ for $5 \mathrm{~min}$ and the cell pellet lysed, treated with DNase and RNase, and soluble and insoluble protein fractions separated by centrifugation. Proteins were fractionated on 10\% acrylamide SDS-PAGE gels at $200 \mathrm{~V}$ for $50 \mathrm{~min}$ and gels subsequently stained with Simply Blue stain (Invitrogen) according to the manufacturer's instructions. The putative thioredoxin peroxidase band was excised from the gel, digested with trypsin and the digest analysed by MALDI TOF mass spectrometry and the resultant peptide masses were analysed using MASCOT databases to confirm protein identity. Recombinant $P o-T P x(r P o-T P x)$ was insoluble and was therefore purified by electro-elution from gels, using an AE3590 Max-Yield GP electro-eluter (ATTO, Japan) according to the manufacturer's instructions.

\section{Immunolocalization of peroxiredoxin}

Antiserum raised against $\mathrm{r} P o-\mathrm{TPx}$ in rabbits using standard methods (e.g. Liddell and Knox, 1998) was used to probe mite sections. Mites were fixed in Carnoy's fluid (60\% ethanol, $30 \%$ chloroform, $10 \%$ acetic acid), then embedded in paraffin wax and $5 \mu \mathrm{m}$ sections cut and dried onto Superfrost slides. Sections were dewaxed in xylene and graduations of alcohol, then rinsed with Tris-buffered saline (TBS). A DAKO (UK) EnVision kit was used to visualize immunolabelled proteins. Peroxidase blocking solution (DAKO) was used to remove any endogenous peroxidase, before blocking with $25 \%$ goat serum diluted in TBS. Sections were probed with either pre-immune sera or sera raised in rabbits against $\mathrm{rPo}-\mathrm{TPx}$ and incubated overnight at $4{ }^{\circ} \mathrm{C}$. Slides were then rinsed with TBS before incubation with horse-radish peroxidase conjugated anti-rabbit IgG
(DAKO) for $30 \mathrm{~min}$ at room temperature. Sections were rinsed with TBS, and antibody binding was visualized using diaminobenzidine substrate solution (DAKO). Slides were then counter-stained with haemotaxylin and rinsed in Scot's tap water substitute, then dehydrated. Sections were mounted with DPX (a mixture of distyrene and xylene) and viewed with an Olympus BX50 microscope.

\section{Immunoreactivity of recombinant peroxiredoxin with sheep sera}

rPo-TPx was electrophoresed under reducing conditions on $10 \%$ acrylamide gels at $200 \mathrm{~V}$ for $50 \mathrm{~min}$, and then blotted onto a nitrocellulose membrane. The membrane was blocked in 5\% Marvel milk in TBST overnight at $4{ }^{\circ} \mathrm{C}$. After blocking, membranes were incubated with serum from infected or naïve sheep (diluted 1 in 200 in TBST) for $3 \mathrm{~h}$ at room temperature with constant shaking. Blots were washed in TBST, before incubation for $1 \mathrm{~h}$ at room temperature with horse-radish peroxidase (HRP) conjugated secondary antibody, diluted 1 in 2000 in TBST. The blots were then washed again in TBST before probing with diaminobenzidine (DAB) substrate (Sigma) for $3-5 \mathrm{~min}$ to visualize proteins.

\section{Enzyme-linked immunosorbent assay}

Serum antibody responses were quantified, in triplicate by enzyme-linked immunosorbent assays (ELISAs). Proteins were bound to ELISA plates by diluting to a concentration of $10 \mu \mathrm{g} / \mathrm{ml}$ in bicarbonate coating buffer (15 mu Na $\mathrm{CO}_{3}, 35 \mathrm{~mm} \mathrm{NaHCO}, \mathrm{pH}$ 9.6), and adding $50 \mu \mathrm{l}$ to each well of the plate (leaving 1 row of wells empty as blanks). Plates were sealed and incubated overnight at $4{ }^{\circ} \mathrm{C}$. Contents of the plates were expelled and the plates washed 6 times in PBST after which they were blocked with $10 \%$ Marvel milk in PBST for $1 \mathrm{~h}$ at room temperature, and then washed another 6 times with PBST. Then $50 \mu \mathrm{l}$ of the appropriate antibody (at varying dilutions) was added to wells, and plates were sealed and incubated at room temperature for $2 \mathrm{~h}$. The plates were again washed 6 times in PBST, and then incubated with horse-radish peroxidase conjugated donkey anti-sheep IgG (Scottish antibody production unit, $50 \mu \mathrm{l}$ per well diluted $1: 500$ in PBST containing $10 \%$ Marvel) for $2 \mathrm{~h}$ at room temperature. Then the plates were washed 6 times in PBST and antibody detected by addition of $50 \mu \mathrm{l}$ of o-phenylenediamine dihydrochloride solution (Sigma) into each well, followed by incubation for 3-5 min to allow colour formation. The reaction was stopped by addition of $50 \mu \mathrm{l}$ of $0.25 \mathrm{M} \mathrm{H}_{2} \mathrm{SO}_{4}$ to each well and absorbance was measured at $490 \mathrm{~nm}$ using an ELISA plate reader. Significant differences were sought using the paired Student's $t$-test. 
Brugia

Avitieae

Fasciola

Schistosoma

Trypanosoma

Aedes

Glossina

Human

Mus

Ixodes

Ornithodoros

Celegans

Psoroptes

Plasmodium

MASLRSARVELAILFIVINLFSTVSLEEACHSFGGGVYPQEFTKASGHNIHWSKAIS 60

Brugia

Avitieae

Fasciola

Schistosoma

Trypanosoma

Aedes

Glossina

Human

Mus

Ixodes

Ornithodoros

Celegans

Psoroptes

Plasmodium

QPAPNFKTTAVVNG-DFKEISLGQFKG-KYVVLLFYPLDFTFVCPTEIIAFSDRIAEFKQ 69 OPAPNFKTTAVMNG-DFKEISLCOFKG-KYVVLFFYPLDFTFVCPTEIIAFSDRIAEFKO 69 MPAPNFSGQAVVGK-EFKTISLSDYKG-KWVILAFYPLDFTFVCPTEIIAFSDOMEQFAR 87 QPAPDFEGTAVIGT-ELRPISLSQFQG-KYVLLVFYPLDFTFVCPTELIAFSERAAEFQS 63 HPAPHFNEVALMPNGTFKKVDLASYRG-KWVVLFFYPLDFTFVCPTEICQFSDRVKEFND 68 KPAPKFSGTAVVNG-AFKEIKLEDYAG-KYLVLFFYPLDFTFVCPTEIIAFSDRVEEFEK 65 ORAPDFKGPAVVKG-AFRDISLTDYRG-KYVVLFFYPLDFTFVCPTEIVAFSDRADEFRN 63 KPAPDFKATAVVDG-AFKEVKLSDYKG-KYVVLFFYPLDFTFVCPTEIIAFSNRAEDFRK 67 KSAPDFTATAVVDG-AFKEIKLSDYRG-KYVVLFFYPLDFTFVCPTEIIAFSDHAEDFRK 67 KPAPDFTGTAVVDG-EFKEFKLSDFKG-KYLVFFFYPLDFTFVCPTEIIAFSDRVKEFKA 118 EPAPYFAGTAVVDG-EFKEIKLTDYKG-KYLVLFFYPLDFTFVCPTEIIAFSDSAEEFRK 65 NTVPAFKGTAVVDG-DFKVISDODYKG-KWLVMFFYPLDFTFVCPTEIIAYGDRANEFRS 94 RQAPYFAATAVVDK-QFKEVKLTDFQG-KYLVLFFYPLDFTFVCPTEIIAFNDRLKEFHD 77 KKAYNFTAQGLNKNNEI INVDLSSFIGQKYCCLLFYPLNYTFVCPTEIIEFNKHIKDFEN 83

Brugia

Avitieae

Fasciola

Schistosoma

Trypanosoma

Aedes

Glossina

Human

Mus

Ixodes

Ornithodoros

Celegans

Psoroptes

Plasmodium

LDVAVMACSTDSHFSHLAWVNTDRKMGGLGQMNIPILAYTNHVISRAYGVLKEDDGIAYR 129 LDVAVMACSTDSHFSHLAWVNTDRKMGGLGPMNIPILADTNHEISRAYGVLKEDDGIAYR 129 RNCAVIFCSTDSVYSHLQWTKMDRKVGGIGQLNFPLLADKNMS ISRAYGVLDEEQGNTYR 147 RGCQVIACSTDSVYAHLAWTKLDRKAGGLGQMNI PLLSDKNLRISRAYEVLDEQEGHAFR 123 VDCEVIACSMDSEFSHLAWTNVERKKGGLGTMNI PILADKTKSIMKAYGVLKEEDGVAYR 128 IGCSVIGVSTDSHFTHLAWINTPRKOGGLGELRI PLLADKSMKISRDYGVLOEESGVPFR 125 IGCEVIACSTDSQYTHLAWVNTPRRQGGLGELDIPLLADKSMKIAREYGVLNEETGIPFR 123 LGCEVLGVSVDSQFTHLAWINTPRKEGGLGPLNI PLLADVTRRLSEDYGVLKTDEGIAYR 127 LGCEVLGVSVDSQFTHLAWINTPRKEGGLGPLNI PLLADVTKSLSQNYGVLKNDEGIAYR 127 LNAEVIACSVDSPFTHLAWINTPRKQGGLGPIKIPLLSDLTHQISKDYGVYLEDLGHSLR 178 INCEIVACSADSHFCHLAWINTPRKEGGLGSMNI PLLADKSCAVSRAYGVLKEDEGIPFR 125 LGAEVVACSCDSHFSHLAWVNTPRKDGGLGDMDI PLLADFNKKIADSFGVLDKESGLSYR 154 LDTEVVAVSVDSHFSHLAWCNTPRKQGGLGDMKMPIISDLTKKISEDYGVLIPDAGIALR 137 KNVELLGISVDSVYSHLAWKNMPIEKGGIGNVEFTLVSDINKDISKNYNVLYDN-SFALR 142

Brugia

Avitieae

Fasciola

Schistosoma

Trypanosoma

Aedes

Glossina

Human

Ixodes

Ornithodoros

Celegans

Psoroptes

Plasmodium

GLFI IDPKGILGQITINDLPVGRSVDETLRLIQAFQFVDKHGEVCPANWHPGSETIKPGV 189 GLFI IDPKGILRQITINDLPVGRSVDETLRLIQAFQFVDKHGEVCPANWHPGSETIKPGV 189 GNFLIDPKGVLRQITVNDRPVGRSVEEALRLLDAFIFHEEHGEVCPANWKPKSKTIVPTP 207 GMFLIDRKGILROITVNDRPVGRSVDEAIRLLDAFIFFEKHGEVCPANWKPNSATIKPDP 183 GLFI IDPOONLROITINDLPVGRNVDETLRLVKAFOFVEKHGEVCPANWKPGSKTMKADP 188 GLFVIDGKQNLRQVTVNDLPVGRSVDETLRLVQAFQFTDEHGEVCPANWKPGSKTMVADP 185 GLFI IDKNQILRQITINDLPVGRSVDETLRLVQAFQFTDEHGEVCPANWKPGQKTMAADP 183 GLFI IDGKGVLRQITVNDLPVGRSVDEALRLVQAFQYTDEHGEVCPAGWKPGSDTIKPNV 187 GLF I IDAKGVLROITVNDLPVGRSVDEALRLVQAFOYTDEHGEVCPAGWKPGSDTIKPNV 187 GLF I IDDKGKLRQITMNDLPVGRSVDETLRLVQAFQYTDKHGEVCPAGWKPGGDTI IPNP 238 GLFI IDDKQRLRQITVNDLPVGRSVEETLRLVQAFQFTDKNGEVCPANWKPGGDTMRPDP 185 GLFLIDPSGTVRHTTCNDLPVGRSVDETLRVLKAFQFSDKHGEVCPADWHEDSPTIKPGV 214 GLF I IDANGIVRQITINDLPVGRSVDETLRLI KAFQYTDKHGEVCPANWQPNEPTINP - - 195 GLF I IDKNGCVRHQTVNDLPIGRNVQEVLRTIDS I I HVDT SGEVCP INWKKGOKAFKPTT 202

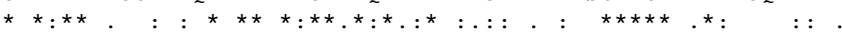

Brugia

Avitieae

Fasciola

Schistosoma

Trypanosoma

Aedes

Glossina

Human

Mus

Ixodes

Ornithodoros

Celegans

Psoroptes

Plasmodium

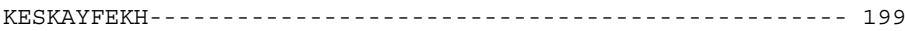

KESKAYFQNIENEPLYNVDQLSNFFNICVLNTFDEYGISALLYSVILIVLDDIICRFL 247

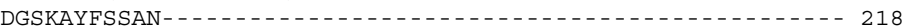

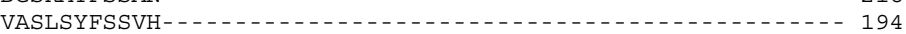

NGSQDYFSSMN- -

QKSKEYFNAAN-

RKSKEYFAATS- - - - - -

DDSKEYFSKHN- - . - _. -

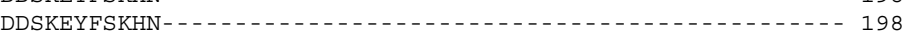

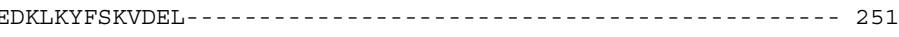

KGSKAYFSKQ - - - - - - - - 195

ATSKEYFNKVNK-- - -

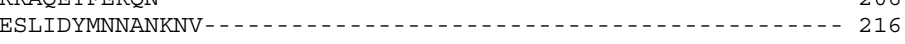

Fig. 1. Amino acid alignment of the Psoroptes ovis TPx sequence with sequences from the mosquito Aedes aegypti (Q8WSF6), the savannah tsetse fly Glossina morsitans morsitans (Q694A6), the soft tick affecting rodents and man Ornithidoros parkeri, human (P32119), mouse (Q61171; the deer tick, Ixodes scapularis (Q4PN30), the trematodes Fasciola hepatica (P91883) and Schistosoma mansoni (Q97161); the apicomplexan Plasmodium falciparum (Q9BKL4); the kinetoplast Trypanosoma brucei rhodesiense; the filarial nematodes Brugia malayi (Q9BMK6) and Acanthocheilonema viteae (Q8T4L6) and the free-living nematode Caenorhabditis elegans (Q21824) and the sheep scab mite Psoroptes ovis. Accession numbers are in parentheses. The sequences highlighted in bold are the two peroxiredoxin motifs essential for 
RESULTS

\section{Peroxiredoxin activity}

Peroxiredoxin activity was detected in mite extracts as judged by a consistently linear change in absorbance correlated $(r=0.986)$ to differing amounts of mite extract added. Activity was optimal at $\mathrm{pH} 8$ but the $\mathrm{pH}$ range for activity was notably narrow with high specific activity only noted at this $\mathrm{pH}$ (not shown).

\section{Sequence analysis}

The open reading frame for Po-TPx (Accession number FJ232038) was 618 nucleotides long and encoded a 206 amino acid protein sequence. This had a predicted molecular mass of $23.4 \mathrm{kDa}$ and a $\mathrm{pI}=6.09$ (http://us.expasy.org/tools/pi_tool.html). Po-TPx showed $60 \%$ amino acid identity (72\% similarity) to peroxiredoxin from the deer tick, I. scapularis, and $60 \%$ identity ( $76 \%$ similarity) to peroxiredoxin from the mosquito Aedes aegypti. An amino acid alignment of $P_{o}-\mathrm{TPx}$ with these sequences and others is shown in Fig. 1. The sequence contained 2 peroxiredoxin motifs essential for enzyme activity (Lim et al. 1998) and both are highly conserved in the $P$. ovis sequence. The protein lacks a predicted signal peptide and has no predicted Nlinked glycosylation sites. Phylogenetic analysis (not shown) indicated that the $P$. ovis sequence formed a branch on its own and is even quite distinct from other members of the Acari, e.g. the I. scapularis sequence, on this basis.

\section{Expression and immunolocalization of peroxiredoxin}

Po-TPx was expressed as a recombinant protein $(\mathrm{r} P o-\mathrm{TPx})$ with a hexa-His-tag in $\mathrm{pET}-22 \mathrm{~b}$ vector. The protein was found in the insoluble pellet of bacterial cells, and migrated at $23 \mathrm{kDa}$ on $10 \%$ acrylamide SDS-PAGE gels (not shown). MALDITOF analysis confirmed that the protein was peroxiredoxin. This protein was used to raise antisera to $\mathrm{rPo}$-TPx produced in rabbits for use in immunolocalization studies, immunoblots and for ELISA analyses.

Mite sections were probed with anti-rPo-TPx and particularly intense staining was evident posterior to the mouthparts and also on the stomach lining compared to similar sections probed with preimmunization serum (Fig. 2).

\section{Immunoreactivity of peroxiredoxin}

rPo-TPx was blot-transferred onto nitrocellulose membranes and probed with sera from sheep infected with $P$. ovis, or naïve to the parasite. IgG from sheep experimentally infested with the $P$. ovis reacted with the recombinant protein, whilst $\mathrm{IgG}$ from naïve sheep did not recognize the protein (Fig. 3). In addition, rPo-TPx was recognized $(P<0 \cdot 0012)$ by sheep carrying a natural infestation (mean $\mathrm{OD}=0.069$; range $0 \cdot 045-0 \cdot 125$ ) compared to uninfested controls (mean $\mathrm{OD}=0.033$; range 0.025-0.051, Fig. 4). Moreover, sheep vaccinated with a partially protective mite extract (Smith and Pettit, 2004) were all seropositive to rPo-Tpx, although the difference was not statistically significant (Fig. 4).

\section{DISCUSSION}

An EST study by Kenyon et al. (2003) revealed several antioxidants may be present in the scab mite, including glutathione S-transferase, superoxide dismutase and thioredoxin peroxidase (peroxiredoxin)encoding ESTs.

Here, the presence of active peroxiredoxin has been confirmed by enzyme activity assays (not shown). The native enzyme had optimal activity at $\mathrm{pH} 8$ which is in accord with the $\mathrm{pH}$ of the skin surface in sheep (Jenkinson, 1989). A full-length cDNA encoding a TPx recognized by IgG from infested or vaccinated sheep was isolated and it lacked an N-terminal signal peptide required for secretion via the classical secretion pathway. The sequence itself showed good homology to peroxiredoxins of insect, tick, nematode and mammalian sequences with 2 Cys-containing domains (highlighted in bold in Fig. 1) being highly conserved. Studies in yeast suggest that the $\mathrm{N}$-terminal domain is critical for enzyme activity and the carboxy-terminal domain for dimer formation (Chae et al. 1994). Phylogenetic analysis (not shown) indicated that the $P$. ovis sequence was distinct from sequences derived from ticks such as Ixodes and insect-derived sequences such as Aedes and Glossina and had a relatively ancient and phylogenetically distinct origin compared to the other sequences used for comparison.

As noted above, the Po-TPx lacked a signal peptide which argues against secretion or release from the mite. However, the protein did localize, in part, to a subpharyngeal region which has been suggested as a salivary gland homologue in mites (Mathieson, 1995). Also, Po-TPx is recognized by circulating IgG following natural infestation of sheep, antibody titres being significantly higher in these animals compared to uninfested controls. These observations indicate that the TPx is released from the mite during infestation. It is notable that a salivary glutathione peroxidise from $I$. scapularis does not have a signal

enzyme activity and are highly conserved within the sequences shown here (Lim et al. 1998). The protein does not have a predicted signal peptide and has no predicted N-linked glycosylation sites. $*=$ identical amino acid, $:=$ conserved amino acid substitution $;.=$ semi-conserved amino acid substitution. 

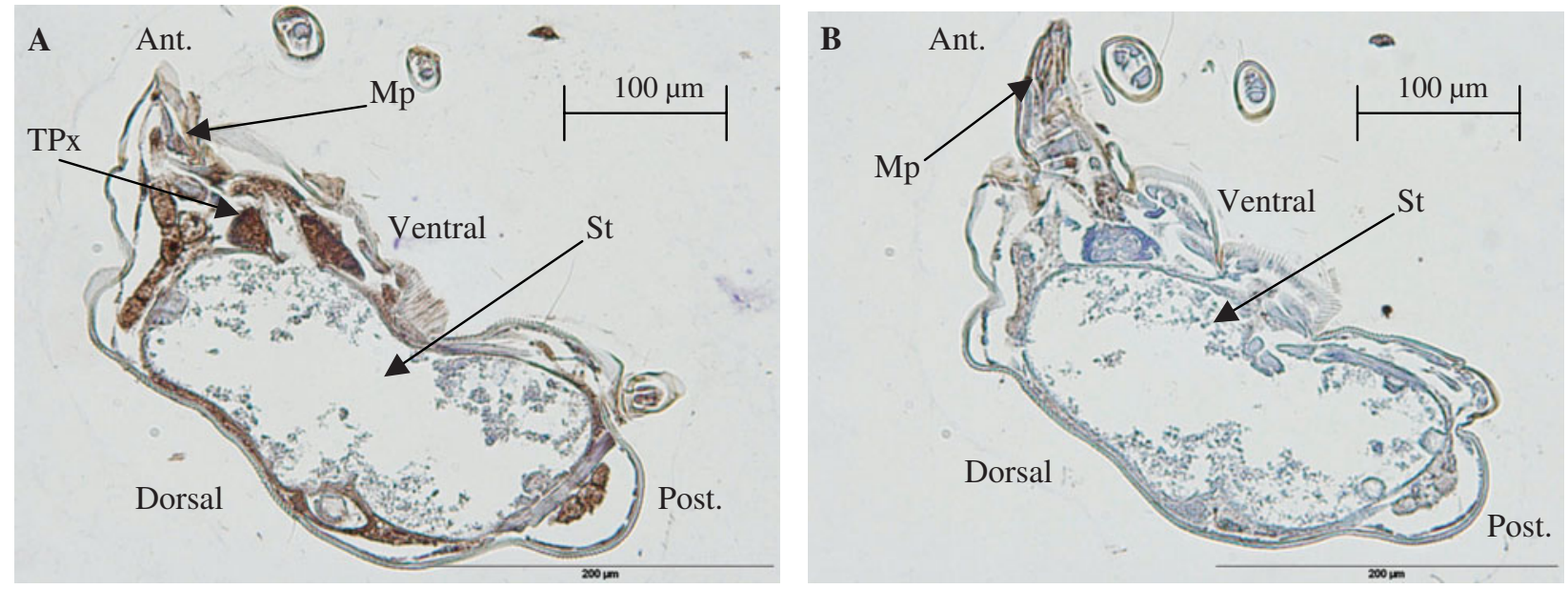

Fig. 2. Localization of peroxiredoxin in longitudinal sections of sheep scab mites. The section shown in (A) was probed with anti-peroxiredoxin serum diluted 1 in 500 in PBS, and the section in (B) was probed with pre-immune serum diluted 1 in 500 in PBS. Staining was particularly intense posterior to the mouthparts and was also evident on the stomach lining. MP, mouth parts; St, stomach; Tpx, peroxiredoxin localization; Ant., anterior end of mite; Post., posterior end of mite; dorsal, dorsal side of mite; ventral, ventral side of mite.

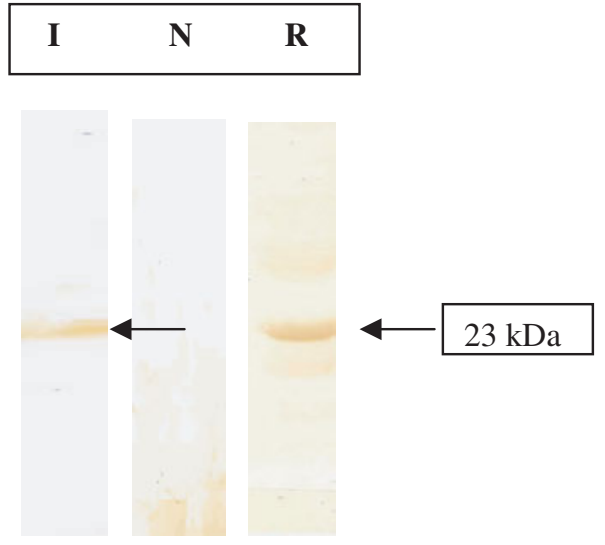

Fig. 3. Reaction of sera from infested and naïve sheep with recombinant peroxiredoxin. Recombinant peroxiredoxin was electrophoresed on a $10 \%$ acrylamide gel, before blotting to nitrocellulose and incubating with either pooled sera from infested sheep $(\mathbf{I})$, pooled sera from naïve sheep $(\mathbf{N})$ or sera from rabbits $(\mathbf{R})$ injected with recombinant TPx, followed by incubation with a horse-radish peroxidase-labelled secondary antibody. Immunoreactive proteins were visualized by development with diaminobenzidine (DAB) substrate. A strong band of recognition was visible on the blot incubated with the rabbit anti-TPx serum ( $R$, arrowed) and a weaker band was evident on the blot strip probed with infestation sera (I, also arrowed), indicating that peroxiredoxin is immunogenic in sheep during infestation. No bands were visible on the blot with naïve serum $(\mathrm{N})$.

peptide but is an immunodominant antigen in the tick saliva (Das et al. 2001). Moreover, a peroxiredoxin from the hard tick Haemaphysalis longicornis localizes to the salivary glands, is recognized by sera from rabbits repeatedly infested with the tick yet lacks an N-terminal signal sequence marking it for secretion (Tsuji et al. 2001). Proteins lacking this

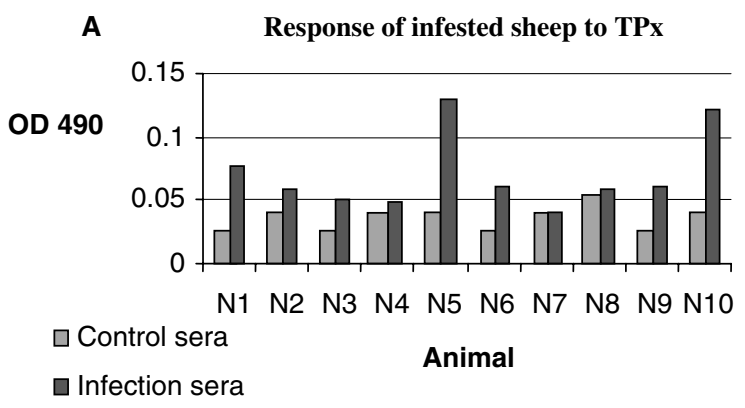

B

Response of vaccinated sheep to TPx

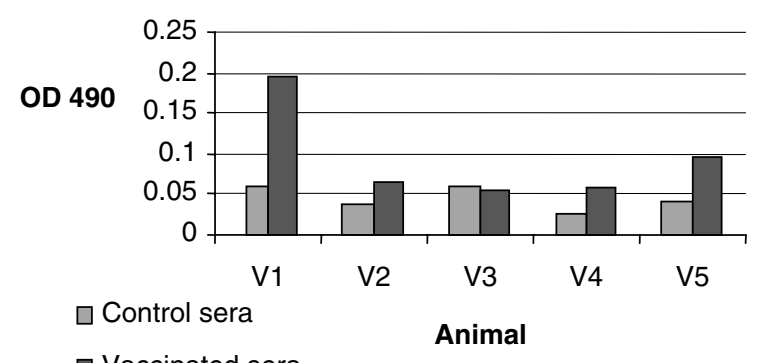

Fig. 4. ELISA analysis of serum IgG responses of individual sheep naturally infested with Psoroptes ovis (A) or vaccinated with a soluble mite fraction $(\mathrm{B})$ previously shown to confer protective immunity when evaluated as a vaccine (Smith and Pettit, 2004). Samples were analysed in triplicate and the maximum coefficient of variation was $9 \cdot 3 \%$.

signal can be released by other mechanisms such as ATP-driven membrane translocators (Kuchler and Thorner, 1992), or by holocrine secretion. Type II epithelial cells in the midgut of ticks have been observed to bud off into the lumen, degrade and burst, releasing their contents (including enzymes) into the midgut lumen (Akov, 1982). In theory, it is possible that the mite peroxiredoxin is released from cells in 
this way given that the enzyme was also detected on the surface of the gut.

The full length sequence of this protein showed $60 \%$ identity to a peroxiredoxin from the deer tick, I. scapularis. The sequence encoding this particular tick enzyme originates from a salivary gland cDNA library (Ribeiro et al. 2006). The properties of tick saliva have been well studied in the past, and include immunomodulatory effects such as anti-coagulation, vasodilation and immunosuppression (Hovius et al. 2008), making them possible targets for vaccination and other control methods. In addition, peroxiredoxins released from the liver fluke Fasciola hepatica polarize a Th2 type host immune response rather than Th1 in infected animals (Donnelly et al. 2005). This type of immune response in fluke infection seems to benefit the parasite more than the host, suggesting that peroxiredoxin is adapting the host immune response for the parasite's own advantage. The host immune response observed in sheep scab has been shown to be more advantageous to the parasite than the host. Huntley et al. (2005) treated sheep with the immunosuppressant drug cyclosporin A, and found that immuno-compromised sheep had significantly smaller lesions, and lower numbers of mites than control sheep. This negative effect on the mites was likely to be due to the immunosuppression, and not a direct effect of the cyclosporin itself, as mites treated with the drug in vitro were unaffected (Huntley et al. 2005). This would suggest that the sheep's immune response benefits the parasite. Indeed, mites have been observed to ingest eosinophils (Mathieson, 1995) and immunoglobulin (Petit et al. 2000), suggesting that elements of the host immune response may provide a food source for them. The mite TPx may protect the gut cells from harmful antioxidant damage which may arise from ingesting eosinophils.

Antioxidant enzymes have been investigated as vaccine candidates in a number of parasitic species. In the porcine tapeworm, Taenia solium, several antioxidant enzymes have been identified as potential vaccine targets due to their wide variety of roles in protecting the worm from host defences and helping them to develop in the host (Vaca-Paniagua et al. 2008). In schistosomes, vaccinating mice with a parasite superoxide dismutase prior to infection resulted in a $54 \%$ decrease in the number of cercariae (LoVerde et al. 2004). Similarily, sheep vaccinated with recombinant superoxide dismutase from the abomasal nematode Haemonchus contortus were partially protected against subsequent homologous challenge (Liddell and Knox, 1998). Sheep vaccinated with a water-soluble $P$. ovis extract had markedly reduced lesion sizes and mite numbers compared to unvaccinated controls when exposed to experimental challenge (Smith and Pettit, 2004). Four of five vaccinates tested here recognized rPo-TPx with 2 particularly strong responders.
However. the group mean ELISA titre was not significantly higher than uninfested controls and, while these data indicate that TPx was a component of this vaccine, it is not possible to associate protection to the presence of TPx in the vaccine.

In conclusion, this study demonstrated peroxiredoxin activity in $P$. ovis extracts and, using antisera to a recombinant version, showed that the protein is localized to a region around the mite's pharynx. This region may represent salivary glands or similar secretory apparatus, and this observation, together with sero-conversion in infested sheep, suggested that the enzyme is secreted from the mite during infestation. If peroxiredoxin is secreted by the mite, and helps to trigger the damaging immune response seen in sheep during infestation, it could be a good target for a recombinant vaccine to confer protection against the disease. Of interest, antibodies to the louse Bovicola ovis present in skin washings from sheep were negatively correlated with the numbers of lice found, suggesting that local antibody responses can contribute to controlling ectoparasite infestations (James, 1999).

The authors gratefully acknowledge funding by the Department for Environment Food and Rural Affairs, UK Research Contract OD0544 and funding by the Scottish Government Rural and Environment Research and Analysis Directorate (RERAD). The authors are grateful to the staff of the Moredun Proteomics Unit for assistance with MALDI-ToF analysis.

\section{REFERENCES}

Akov, S. (1982). Blood digestion in ticks. In Physiology of Ticks (ed. Obenchain, F. D. and Galun, R.), pp. 197-211. Pergamon Press, Oxford, UK.

Chae, H. Z., Chung, S. J. and Rhee, S. G. (1994). Thioredoxin-dependent peroxide reductase from yeast. Fournal of Biological Chemistry 269, 27670-27678.

Clark, A. M., Stephen, F. B., Cawley, G. D., Bellworthy, S. J. and Groves, B. A. (1996). Resistance of the sheep scab mite Psoroptes ovis to propetamphos. Veterinary Record 139, 451.

Das, S., Banerjee, G., DePonte, K., Marcantonio, N., Kantor, F. S. and Fikrig, E. (2001). Salp25D, an Ixodes scapularis antioxidant, is 1 of 14 immunodominant antigens in engorged tick salivary glands. Fournal of Infectious Diseases 184, 1056-1064.

Donnelly, S., O’Neill, S. M., Sekiya, M., Mulcahy, G. and Dalton, J. P. (2005). Thioredoxin peroxidase secreted by Fasciola hepatica induces the alternative activation of macrophages. Infection and Immunity 73, 166-173.

Dyrløv Bendtsen, J., Nielsen, H., von Heijne, G. and Brunak, S. (2004). Improved prediction of signal peptides: SignalP 3.0. Fournal of Molecular Biology 340, 783-795.

Hovius, J. W., Levi, M. and Fikrig, E. (2008). Salivating for knowledge: potential pharmacological agents in tick saliva. PLoS Medicine 5, e43.

Huntley, J. F., van den Broek, A., Machell, J., Mackellar, A., Pettit, D., Meikle, L., Barcham, G., 
Meeusen, E. N. and Smith, W. D. (2005). The effect of immunosuppression with cyclosporin A on the development of sheep scab. Veterinary Parasitology 127, 323-332.

James, P. J. (1999). Do sheep regulate the size of their mallophagan louse populations? International Fournal for Parasitology 29, 869-875.

James, P. J., Moon, R. D. and Ragsdale, D. W. (1998). Skin surface antibodies and their associations with sheep biting lice, Bovicola ovis, on experimentally infested sheep. Medical and Veterinary Entomology 12, 276-283.

Jeanmougin, F., Thompson, J. D., Gouy, M., Higgins, D. G. and Gibson, T. J. (1998). Multiple sequence alignment with Clustal X. Trends in Biochemical Sciences 23, 403-405.

Jenkinson, D. M. E. (1989). Skin surface responses to external challenge. In Practice 11, 207-209.

Kenyon, F., Welsh, M., Parkinson, J., Whitton, C., Blaxter, M. L. and Knox, D. P. (2003). Expressed sequence tag survey of gene expression in the scab mite Psoroptes ovis - allergens, proteinases and free radical scavengers. Parasitology 126, 451-460.

Kuchler, K. and Thorner, J. (1992). Secretion of peptides and proteins lacking hydrophobic signal sequences: the role of adenosine triphosphate-driven membrane translocators. Endocrinological Reviews 13, 499-514.

Liddell, S. and Knox, D. P. (1998). Extracellular and cytoplasmic $\mathrm{Cu} / \mathrm{Zn}$ superoxide dismutases from Haemonchus contortus. Parasitology 116, 383-394.

Lim, M. J., Chae, H. Z., Rhee, S. G., Yu, D. Y., Lee, K. K. and Yeom, Y. I. (1998). The type II peroxiredoxin gene family of the mouse: molecular structure, expression and evolution. Gene 216, 197-205.

LoVerde, P. T. (1998). Do antioxidants play a role in Schistosome host-parasite interactions? Parasitology Today 14, 284-289.

Lo Verde, P. T., Carvalho-Queiroz, C. and Cook, R. (2004). Vaccination with antioxidant enzymes confers protective immunity against challenge infection with Schistosoma mansoni. Memórias do Instituto Oswaldo Cruz 99, 37-43.

Mathieson, B. R. (1995). An investigation of Psoroptes ovis, the sheep scab mite, with a view to developing an in vitro feeding system. Ph.D. thesis, University of Aberstywyth, Wales, UK.

Nieuwhof, G. J. and Bishop, S. C. (2005). Costs of the major endemic diseases of sheep in Great Britain and the potential benefits of reduction in disease impact. Animal Science 81, 23-29.
Nisbet, A. J. and Huntley, J. F. (2006). Progress and opportunities in the development of vaccines against mites, fleas and myiasis-causing flies of veterinary importance. Parasite Immunology 28, 165-172.

Nisbet, A. J., Halliday, A. M., Parker, L., Smith, W. D., Kenyon, F., Knox, D. P. and Huntley, J. F. (2008). Psoroptes ovis: identification of vaccine candidates by immunoscreening. Experimental Parasitology 120, 194-199.

Pettit, D., Smith, W. D., Richardson, J. and Munn, E. A. (2000). Localisation and characterisation of ovine immunoglobulin within the sheep scab mite, Psoroptes ovis. Veterinary Parasitology 89, 231-239.

Ribeiro, J. M., Alarcon-Chaidez, F., Francischetti, I. M., Mans, B. J., Mather, T. N., Valenzuela, J. G. and Wikel, S. K. (2006). An annotated catalog of salivary gland transcripts from Ixodes scapularis ticks. Insect Biochemistry and Molecular Biology 36, 111-129.

Shalaby, K. A., Yin, L., Thakur, A., Christen, L., Niles, E. G. and LoVerde, P. T. (2003). Protection against Schistosoma mansoni utilizing DNA vaccination with genes encoding $\mathrm{Cu} / \mathrm{Zn}$ cytosolic superoxide dismutase, signal peptide-containing superoxide dismutase and glutathione peroxidase enzymes. Vaccine 22, 130-136.

Smith, W. D. and Pettit, D. M. (2004). Immunization against sheep scab: preliminary identification of fractions of Psoroptes ovis which confer protective effects. Parasite Immunology 26, 307-314.

Synge, B. A., Bates, P. G., Clark, A. M. and Stephen, F. B. (1995). Apparent resistance to flumethrin. Veterinary Record 137, 51.

Tauber, A. I., Goetz1, E. J. and Babior, B. M. (1979). Unique characteristics of superoxide production by human eosinophils in eosinophilic states. Inflammation 3, 261-272.

Tsuji, N., Kamio, T., Isobe, T. and Fujisaki, K. (2001). Molecular characterization of a peroxiredoxin from the hard tick Haemaphysalis longicornis. Insect Molecular Biology 10, 121-129.

Vaca-Paniagua, F., Torres-Rivera, A., Parra-Unda, R. and Landa, A. (2008). Taenia solium: antioxidant metabolism enzymes as targets for cestocidal drugs and vaccines. Current Topics in Medicinal Chemistry 8, 393-399.

van den Broek, A. H., Huntley, J. F., MacHell, J., Taylor, M., Bates, P., Groves, B. and Miller, H. R. (2000). Cutaneous and systemic responses during primary and challenge infestations of sheep with the sheep scab mite, Psoroptes ovis. Parasite Immunology 22, $407-414$. 